\title{
Paper
}

\section{Fabrication of Diamond/SiC Composites Using HIP from Mixtures of Diamond and Si Powders}

\author{
Ken HIROTA ${ }^{1 *}$, Motoyasu AOKI ${ }^{1}$, Masaki KATO ${ }^{1}$, Minoru UEDA ${ }^{2}$ and Yoichi NAKAMORI ${ }^{2}$ \\ ${ }^{1}$ Department of Molecular Chemistry \& Biochemistry, Faculty of Science \& Engineering, Doshisha University, Kyoto 610-0321, Japan. \\ ${ }^{2}$ Metal Technology Co., Ltd., 1-32-2 Honcho, Nakano-ku, Tokyo 164-8721, Japan.
}

Received August 28, 2018; Revised November 14, 2018; Accepted November 26, 2018

\begin{abstract}
Diamond/SiC $=75 / 25 \sim 50 / 50$ vol\% composites were fabricated utilizing liquid-phase reaction sintering during hot isostatic pressing (HIP) at $1723 \mathrm{~K}$ under $196 \mathrm{MPa}$ for $7.2 \times 10^{3} \mathrm{~s}$ from mixtures of four kinds of diamond (average particle size $P_{\mathrm{s}}$ of $69,60,9.2$, and $\left.3.5 \mu \mathrm{m} \phi\right)$ and $\mathrm{Si}\left(P_{\mathrm{s}}: 0.6 \mu \mathrm{m} \phi\right)$ powders. After the starting powders were mixed for $1.8 \times 10^{3} \mathrm{~s}$ in ethanol, the mixtures were dried and compacted uniaxially (50 MPa) and isostatically $(245 \mathrm{MPa})$. They were preheated at $1223 \mathrm{~K}$ for $7.2 \times 10^{3} \mathrm{~s}$ in a vacuum (Process (I)) or solidified using pulsed electric-current pressure sintering (PECPS) at $1623 \mathrm{~K}$ and $50 \mathrm{MPa}$ for $0.6 \times 10^{3} \mathrm{~s}$ under reduced pressure (Process (II)). The compacts prepared via Process (I) and Process (II) were densified by Pyrex glass capsule HIPing $\left(1723 \mathrm{~K} / 7.2 \times 10^{3} \mathrm{~s} / 196 \mathrm{MPa} / \mathrm{Ar}\right.$ ). High relative density (around 93\%) was achieved at the composition of diamond $/ \mathrm{SiC}=55 / 45 \mathrm{vol} \%$ using bimodal diamond powders, i.e., an average $P_{\mathrm{s}}$ of around $50 \mu \mathrm{m} \phi$ and Process (II). In order to improve Vickers hardness $\left(H_{\mathrm{v}}\right)$, a small amount of $\mathrm{B}_{4} \mathrm{C}\left(P_{\mathrm{s}}: 0.5 \mu \mathrm{m} \phi\right)$ powders was added to [diamond (69:3.5 $\mu \mathrm{m} \phi=7: 3)] / \mathrm{SiC}=55 / 45 \mathrm{vol} \%$ composite using Process (II) at $1623 \mathrm{~K}$ followed by HIP. Both the relative density and $H_{\mathrm{v}}$ values increased substantially, from 89 to $95.0 \%$ and from 38.7 to $51.3 \mathrm{GPa}$ at $10 \mathrm{vol} \% \mathrm{~B}_{4} \mathrm{C}$ addition, respectively.
\end{abstract}

\section{KEY WORDS}

diamond, $\mathrm{SiC}, \mathrm{B}_{4} \mathrm{C}$, liquid-phase reaction sintering, Vickers hardness

\section{Introduction}

To satisfy the continuously increasing need for novel materials and properties, hard inorganic materials have been attracting a lot of attention. Among them, diamond is the hardest material (Vickers hardness $H_{\mathrm{v}}: \sim 150 \mathrm{GPa}$ ), and it has high mechanical and thermal properties (Young's modulus E: $1050 \mathrm{Gpa}$; thermal conductivity $\sigma_{\mathrm{t}}: 600 \sim 2000 \mathrm{~W} \cdot \mathrm{m}^{-1} \cdot \mathrm{K}^{-1}$ ), as shown in Table 1 . Since the invention of artificial diamond in 1955 by Bundy et al. of General Electric ${ }^{1)}$, there have been many attempts to fabricate polycrystalline diamond $(\mathrm{PCD})^{2)}$ under diamond's thermodynamically stable region, such as 5 6 GPa and 2073 2173 $\mathrm{K}^{3)}$. On the other hand, few experiments have been attempted in the metastable region ${ }^{4)}$. M. Shimono and $\mathrm{S}$. Kume ${ }^{5}$ studied the fabrication of diamond/ $\mathrm{SiC}$ composites from diamond and $\mathrm{Si}$ powders utilizing liquid-phase reaction sintering: $2 \mathrm{C}+\mathrm{Si} \rightarrow \mathrm{C}($ diamond $)+\mathrm{SiC}$, by a glass-capsule $\mathrm{HIP}$ at the higher temperature of the Si melting point $\left(T_{\mathrm{m}}: 1687 \mathrm{~K}\right)$. They reported a bulk density of $3.2 \sim 3.3 \mathrm{Mg} \cdot \mathrm{m}^{-3}$, i.e., a relative density $\sim 90 \%$, average $H_{\mathrm{v}}$ of $37 \mathrm{GPa}$, and bending strength $\sigma_{\mathrm{b}}$ of $\sim 550 \mathrm{MPa}$ for composites fabricated at $1723 \mathrm{~K}$ for $1.8 \times 10^{3} \mathrm{~s}$ at $50 \mathrm{MPa}$. This process has some good characteristics, such as near net shape and

* Corresponding author, E-mail: kirota@mail.doshisha.ac.jp very mild fabrication conditions. However, it is difficult to control the composition of the diamond-to-SiC ratio, which difficulty often resulted in lower $H_{\mathrm{v}}$ values than expected. For example, the microstructure of a HIPed diamond/SiC composite depends heavily on the starting diamond powder sizes, as shown in Fig. 1 and Table 2.

Recently, a new sintering method called pulsed electric-current pressure sintering (PECPS) has been developed in Japan ${ }^{6}$. This method can solidify poor sinterable powders for a shorter soaking time at lower sintering temperatures than those of conventional electric furnaces ${ }^{7,8)}$. The present authors have been applying this

Table 1 Physical and mechanical properties of diamond, silicon carbide $\beta-\mathrm{SiC}$, and $\mathrm{B}_{4} \mathrm{C}$.

\begin{tabular}{|c|c|c|c|c|c|}
\hline & Symbol & Unit & $\begin{array}{l}\text { diamond } \\
\text { Cubic }\end{array}$ & $\begin{array}{l}\beta-\mathrm{SiC} \\
\text { Cubic }\end{array}$ & $\begin{array}{l}\mathrm{B}_{4} \mathrm{C} \\
\text { Hexa }\end{array}$ \\
\hline Theoretical density & $D_{\mathrm{x}}$ & $\mathrm{Mg} \cdot \mathrm{m}^{-3}$ & 3.513 & 3.21 & 2.515 \\
\hline Vickers hardness & $H_{\mathrm{v}}$ & $\mathrm{GPa}$ & $\sim 150$ & 28 & 33.5 \\
\hline Melting temperature & $T_{\mathrm{m}}$ & K & 2723 & 3003 & 2723 \\
\hline Fracture toughness & $K_{\mathrm{IC}}$ & $\mathrm{MPa} \cdot \mathrm{m}^{1 / 2}$ & 2.0 & 4.0 & 3.1 \\
\hline Young's modulus & E & $\mathrm{GPa}$ & 1050 & 430 & 385 \\
\hline $\begin{array}{c}\text { Thermal expansion } \\
\text { coefficient }\end{array}$ & $\alpha$ & $10^{-6} \mathrm{~K}^{-1}$ & $0.8 \sim 1.2$ & 4.5 & 2.3 \\
\hline Thermal conductivity & $\sigma_{\mathrm{T}}$ & $\mathrm{W} /(\mathrm{mK})$ & $600 \sim 2000$ & 270 & 37 \\
\hline
\end{tabular}



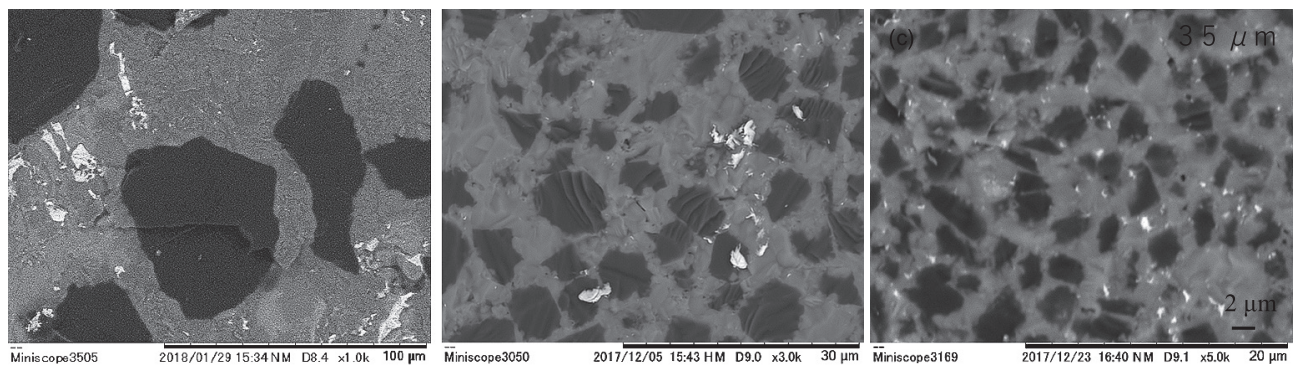

Fig. 1 SEM photographs of SiC-added diamond composites: $P_{\mathrm{s}}$ (diamond), (a) 69, (b) 9.2, and (c) $3.5 \mu \mathrm{m} \phi$.

Table 2 Densities of diamond-SiC composite fabricated by HIP.

\begin{tabular}{ccccc}
\hline $\begin{array}{c}P_{\mathrm{s}} \text { of diamond } \\
(\mu \mathrm{m})\end{array}$ & $\begin{array}{c}\text { Volume } \\
\text { fraction of } \\
\text { diamond }\end{array}$ & $\begin{array}{c}D_{\mathrm{obs}} \\
\left(\mathrm{Mg} \cdot \mathrm{m}^{-3}\right)\end{array}$ & $\begin{array}{c}D_{\mathrm{x}} \\
\left(\mathrm{Mg} \cdot \mathrm{m}^{-3}\right)\end{array}$ & $\begin{array}{c}D_{\mathrm{obs}} / D_{\mathrm{x}} \\
(\%)\end{array}$ \\
\hline 69 & 45 & 3.27 & 3.35 & 97.6 \\
9.2 & 65 & 3.22 & 3.41 & 94.4 \\
3.5 & 70 & 3.24 & 3.42 & 94.7 \\
\hline
\end{tabular}

sintering method to fabricate dense composite materials containing carbon nanofibers (CNF), such as $\mathrm{Al}_{2} \mathrm{O}_{3} / \mathrm{CNF}^{9}$ ) $, \mathrm{SiC} / \mathrm{CNF}^{10)}, \mathrm{SiAlON} /$ $\mathrm{CNF}^{11)}, \mathrm{B}_{4} \mathrm{C} / \mathrm{CNF}^{12,13)}$, and $(\mathrm{Fe}-\mathrm{Ni})$ alloy/ferrite composites ${ }^{14)}$, that could be fabricated just by utilizing short soaking times and lower sintering temperatures.

In the present study, we applied this method to fabricate diamond/ $\mathrm{SiC}$ composites and compare them with those made by nearly the same method as reported ${ }^{5)}$. Furthermore, to improve the $H_{\mathrm{v}}$ value, we added particles of the third hardest material, $\mathrm{B}_{4} \mathrm{C}\left(H_{\mathrm{v}}: 33.5 \mathrm{GPa}\right.$, Table 1), to diamond/SiC composites. This paper describes the properties of (PECPS + HIP)-sintered diamond/SiC composites and also reports on the effect of $\mathrm{B}_{4} \mathrm{C}$ addition.

\section{Experimental procedure}

Fabrication of diamond/SiC composites with a small addition of $\mathrm{B}_{4} \mathrm{C}$ particles

As shown in Fig. 2, the starting materials were four kinds of hydrogen-termination-processed $\left(1073 \mathrm{~K} / 7.2 \times 10^{3} \mathrm{~s} / \mathrm{H}_{2}\right)$ diamond powders $^{15,16)}$ (average particle size $P_{\mathrm{s}}$ of $69,60,9.2$, and $3.5 \mu \mathrm{m} \phi$, IMS-OB 200/230, IMS-OB 230/270, IRM-OB 8-16, and IRMOB 4-6, respectively; Tomei Diamond, Tokyo, Japan), Si ( $P_{\mathrm{s}}$ of 5.0 6.0 $\mu \mathrm{m} \phi$, High Purity Chemical Laboratories, Saitama, Japan),

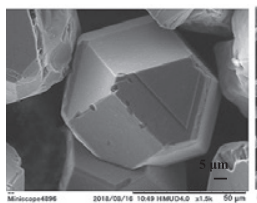

$(69 \mu \mathrm{m} \phi)$

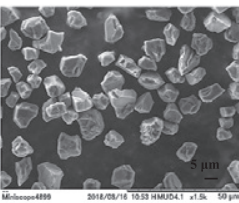

$(9.2 \mu \mathrm{m} \phi)$

Diamond

(Large : small)

$\left(69 \mu \mathrm{m}^{\varphi}\right)\left(3.5\right.$ or $\left.9.2 \mu \mathrm{m}^{\varphi}\right)$

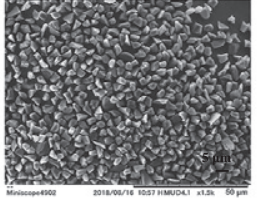

$(3.5 \mu \mathrm{m} \phi)$$$
(3.5,4)
$$

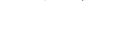

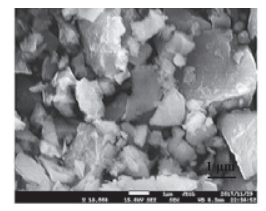

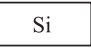

$\left(5 \sim 6 \mu \mathrm{m}^{\varphi}\right)$

(Ball-milling $1600 \mathrm{rpm} / 3.6 \times 10^{3} \mathrm{sec}$ ) $\rightarrow 0.6 \mu \mathrm{m}^{\varphi}$

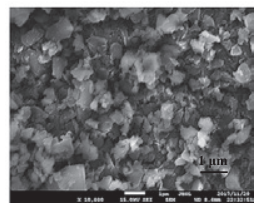

$\mathrm{B}_{4} \mathrm{C}$

$\left(0.5 \mu \mathrm{m}^{\varphi}\right)$

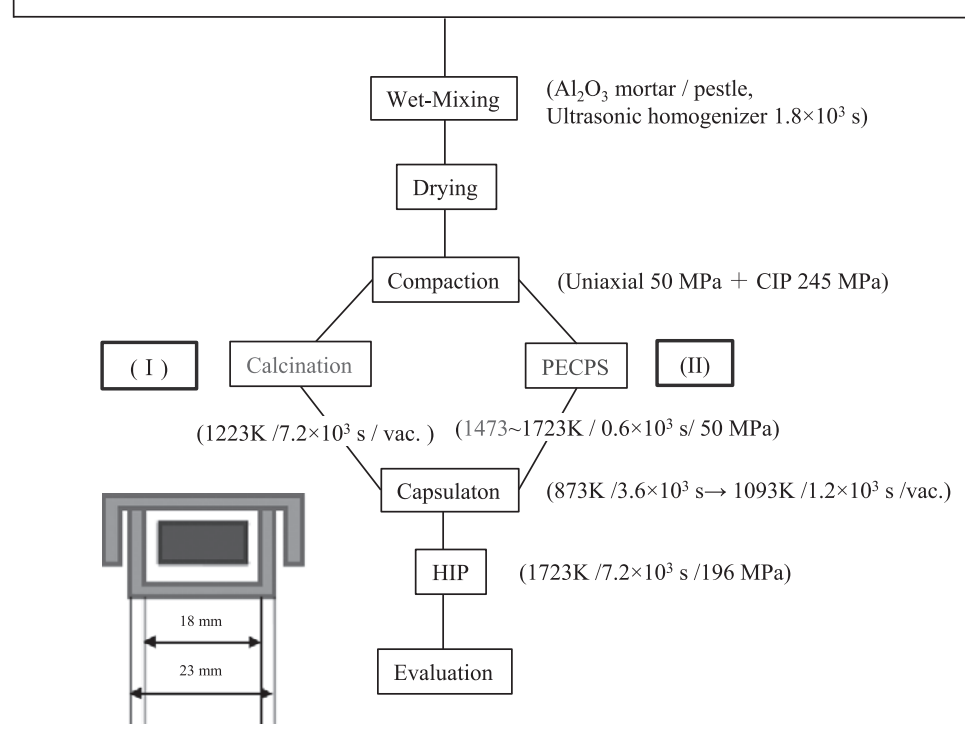

Fig. 2 Flowchart for the fabrication of diamond/SiC. 
and $\mathrm{B}_{4} \mathrm{C}$ ( $P_{\mathrm{s}}$ of $0.5 \mu \mathrm{m} \phi$, High Purity Chemical Laboratories). The diamond powders of $P_{\mathrm{s}}$ of $(69$ or $60 \mu \mathrm{m} \phi)$ and $(9.2$ or $3.5 \mu \mathrm{m} \phi)$ were mixed into 5:5, 7:3, and 9:1 $\operatorname{ratios}^{17)}$. The Si powder was pulverized into $P_{\mathrm{s}}$ of $0.6 \mu \mathrm{m} \phi$ using a bead mill (Easy Nano, AIMEX, Tokyo, Japan) at $2.67 \times 10$ rounds per second $(1600 \mathrm{rpm})$ for $3.6 \times$ $10^{3} \mathrm{~s}$ using $2.0 \mathrm{~mm} \phi$ zirconia balls (Nikkato, Osaka, Japan) in ethanol and Ar. The diamond and pulverized $\mathrm{Si}$, along with $\mathrm{B}_{4} \mathrm{C}$ powders with an inner proportion, were mixed homogeneously using an ultrasonic vibrating homogenizer (US-300T, NihonSeiki Ltd., Tokyo, Japan) with a power output of $300 \mathrm{~W}$ at $20 \mathrm{kHz}$ for $1.8 \times 10^{3} \mathrm{~s}$ in ethanol. After drying, a small amount of $3 \%$ concentration acrylic binder was added to the mixture and compacted uniaxially and isostatically $(245 \mathrm{MPa} / 6.0 \times 10 \mathrm{~s})$. The compressed powder compacts were pre-heat-treated for $3.6 \times 10^{3} \mathrm{~s}$ at $1223 \mathrm{~K}$ under reduced pressure to eliminate the small amounts of water and oxygen adsorbed on the surfaces of diamond and $\mathrm{Si}$ fine powders without particle sintering ${ }^{12,13)}$ or transformation from diamond to graphite during heating ${ }^{3)}$.

On the basis of our preliminary experimental results, the compacts were pre-heated at $1223 \mathrm{~K}$ for $7.2 \times 10^{3} \mathrm{~s}$ Process (I) or solidified using pulsed electric-current pressure sintering (PECPS, SPS-5104A, SPS SYNTEX, Tokyo, Japan) Process (II). After elimination of adsorbed gas and wrapping with $h$-BN powder ( $P_{\mathrm{s}}$ of $\sim 3 \mu \mathrm{m} \phi,>98 \%$ purity, GP, Denka, Tokyo, Japan), they were put into a cylindrical mold $\left(20 \mathrm{~mm}^{\phi}-40 \mathrm{~mm}^{\phi}-40 \mathrm{~mm}^{\mathrm{h}}\right.$, highdensity graphite carbon, Toyo-Tanso, Osaka, Japan) that was used for PECPS. Using this apparatus, sintering was performed at $1473 \sim 1723 \mathrm{~K}$ for $0.6 \times 10^{3} \mathrm{~s}$ under a uniaxial pressure of $50 \mathrm{MPa}$ in a vacuum $(\sim 10 \mathrm{~Pa})$ with a heating rate of $1.66 \mathrm{~K} \cdot \mathrm{s}^{-1}$ and a cooling rate of $\sim 8.33 \times 10^{-1} \mathrm{~K} \cdot \mathrm{s}^{-1}$, applying DC pulse electric current (on/ off interval $=12: 2$ ). Heating above $\sim 873 \mathrm{~K}$ was monitored at the center position of the outside wall of the carbon mold using a monochrome pyrometer.

The acrylic binder was removed by the calcination $(1273 \mathrm{~K} / 7.2 \times$ $10^{3} \mathrm{~s} / \mathrm{vac}$.) in Process (I) and by PECPS in Process (II). Both of the compacts prepared via the two processes were densified by Pyrex glass capsule HIP $\left(1723 \mathrm{~K} / 7.2 \times 10^{3} \mathrm{~s} / 196 \mathrm{MPa} / \mathrm{Ar}\right)$ as shown in Fig. 2, using liquid-phase reaction sintering ${ }^{18)}$ between diamond and $\mathrm{Si}$ at temperatures above the melting point of $\mathrm{Si}(1687 \mathrm{~K})$.

Characterization of samples

Crystalline phases were identified by X-ray diffraction (XRD) analysis ( $\mathrm{CuK \alpha}$ radiation, Rint 22000, Rigaku, Osaka, Japan). Microstructural observation by a field emission-type scanning electron microscope (Miniscope, TM3030Plus, Hitachi High Technologies, Tokyo, Japan) was performed on the fracture surfaces of the sintered materials. As the volume fractions of both diamond and $\mathrm{SiC}$ of HIP sintered composites could not be determined by conventional XRD (Rietveld) or chemical analysis such as ICP due to much difference in XRD scattering power for single crystal diamond and poly-crystal $\mathrm{SiC}$, much difficulty for diamond and $\mathrm{SiC}$ to dissolve into solutions, respectively., they were estimated using an image analysis softwear ("WinROOF 2015, Mitani corporation, Osaka, Japan) applied to the SEM (back scattered image: BEI) images on their polished surfaces. Also, a laser microscope (VK-x200, Keyence, Osaka, Japan) was used to observe the Vickers hardness indent in air. The bulk densities of the sintered samples were measured by the Archimedes method. Vickers hardness $H_{\mathrm{v}}$ was evaluated by applying a load of $9.81 \mathrm{~N}$ and a duration time of $15 \mathrm{~s}$.

\section{Results and discussion}

Difference between Processes I and II

Fig. 3 displays the XRD patterns of diamond (69:9.2 $\mu \mathrm{m} \phi=7: 3) /$ $\mathrm{SiC}$ composites with various $\mathrm{SiC}$ intended contents from 35 to $50 \mathrm{vol} \%$ or 35 to $100 \mathrm{vol} \%$, fabricated as follows: (a) (d), calcined $\left(1223 \mathrm{~K} / 7.2 \times 10^{3} \mathrm{~s} / \mathrm{vac}\right.$.) through Process (I) and (e) (h) sintered by PECPS $\left(1723 \mathrm{~K} / 0.6 \times 10^{3} \mathrm{~s} / 50 \mathrm{MPa} / \mathrm{vac}\right.$.) via Process (II), followed in either case by HIP $\left(1723 \mathrm{~K} / 7.2 \times 10^{3} \mathrm{~s} / 196 \mathrm{MPa} / \mathrm{Ar}\right)$ The differences between Process (I) and Process (II) are as follows. First, when the content of $\mathrm{SiC}$ was increased from 35 to $50 \mathrm{vol} \%$, the amount of graphite $2 \mathrm{H}-\mathrm{C}$ in the HIPed composites decreased in (a) to (d) via Process (I). On the contrary, the amount of graphite increased in (e) and (f) via Process (II). Second, the remaining contents of $\mathrm{Si}$ in the composites were still high in XRD patterns of (b) (d) via Process (I), whereas in Process (II) the amount of unreacted Si was not so high without the diamond $/ \mathrm{SiC}=30 / 70 \mathrm{vol} \%$ composition (in Fig. 3 (g)), suggesting that when a small amount of $\mathrm{Si}$ is added to the diamond powders and then PECPSed at $1723 \mathrm{~K}$, unreacted diamond might transform into graphite. This might be explained by the fact that the dense microstructures of diamond/SiC after PECPS at $1723 \mathrm{~K}$ might block direct contact between diamond and remaining liquid $\mathrm{Si}$, resulting in the suppression of their liquidphase reaction during HIP. Here, the diffraction peaks of $\mathrm{SiC}$ phase in (h) shifted to the lower angles a little less than those for pure $\mathrm{SiC}$, which might be explained by the bulk sample's inclination to the XRD measurement of the datum surface. Fig. 4 (i) to (iv)

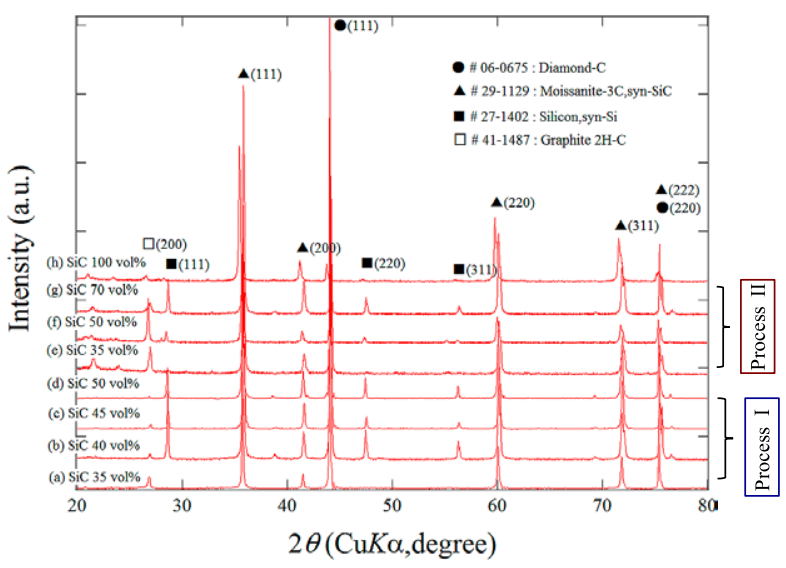

Fig. 3 XRD patterns of diamond/SiC composites: (a) (d), calcined $\left(1223 \mathrm{~K} / 7.2 \times 10^{3} \mathrm{~s} / \mathrm{vac}\right.$.) and (e) (i) sintered by PECPS $(1723 \mathrm{~K} / 0.6 \times$ $10^{3} \mathrm{~s} / 50 \mathrm{MPa} / \mathrm{vac}$.), followed by HIP $\left(1723 \mathrm{~K} / 7.2 \times 10^{3} \mathrm{~s} / 196 \mathrm{MPa} / \mathrm{Ar}\right)$ 


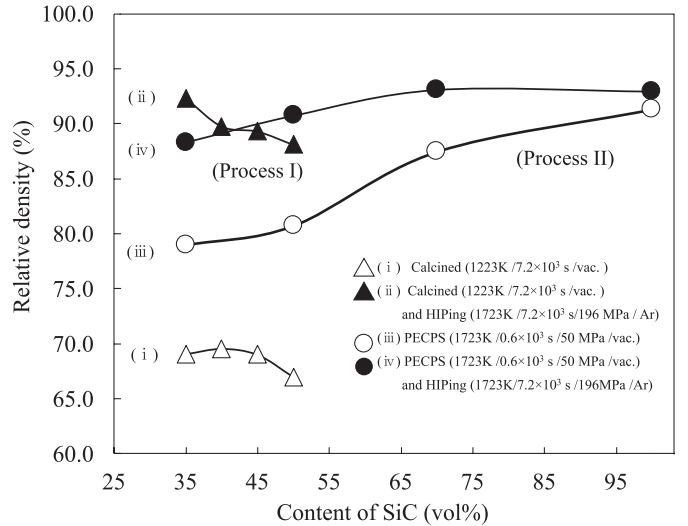

Fig. 4 Relative densities of diamond/SiC composites fabricated under various conditions as a function of $\mathrm{SiC}$ content.

display the relative densities $D_{\mathrm{r}}$, i.e., $D_{\mathrm{r}}=D_{\mathrm{obs}} / D_{\mathrm{x}}$, where $D_{\mathrm{obs}}$ and $D_{\mathrm{x}}$ are the bulk and theoretical densities, respectively. The $D_{\mathrm{r}}$ of diamond (69:9.2 $\mu \mathrm{m} \phi=7: 3) / \mathrm{SiC}$ composites fabricated by two processes, i.e., via Process (I) and Process (II) before and after HIPing, are denoted as (i), (ii), and (iii), (iv), respectively, as a function of the intended content of SiC. In the $D_{\mathrm{r}}$ before HIP, the values of (i), only calcined materials, are much lower than those of PECPSed (iii). This might be due to activated pressing during PECPS heat treatment. Furthermore, a comparison of the $D_{\mathrm{r}}$ values of HIP composites, i.e., (ii) and (iv), showed that Process (II) could give a higher $D_{\mathrm{r}}$ than Process (I).

Then, the most appropriate PECPS temperature was investigated. Fig. 5 shows the dependence of $D_{\mathrm{r}}$ for the diamond/SiC $=$ $75 / 25$ vol\% composites on the PECPS temperature from 1473 to $1673 \mathrm{~K}$; the composites were fabricated using PECPS $(0.6 \times$ $10^{3} \mathrm{~s} / 50 \mathrm{MPa} / \mathrm{vac}$.) followed by HIP $\left(1723 \mathrm{~K} / 7.2 \times 10^{3} \mathrm{~s} / 196 \mathrm{MPa} /\right.$ $\mathrm{Ar}$ ). The lower white circles represent $D_{\mathrm{r}}$ just after PECPS, and the upper black circles represent it after HIP. The most suitable PECPS temperature was considered to be around $1623 \mathrm{~K}$. Then their

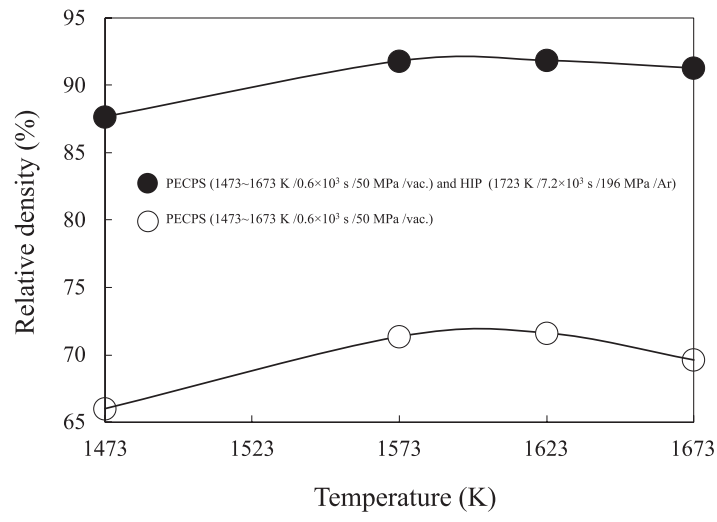

Fig. 5 Relative densities of diamond $/ \mathrm{SiC}=75 / 25$ vol $\%$ composites: (a) (d), PECPS (1473 1673 K/0.6 × 10 3 s/50 MPa/vac.) and (e) (h) followed by HIP $\left(1723 \mathrm{~K} / 7.2 \times 10^{3} \mathrm{~s} / 196 \mathrm{MPa} / \mathrm{Ar}\right)$.

microstructures were observed. Fig. 6 shows SEM photographs of the fracture surfaces of diamond/SiC composites with the $65 / 35$ and 50/50 vol\% compositions. The upper (a) and (b) images show the composites fabricated via Process (I), and the lower (c) and (d) via Process (II). Large diamond particles and small (gray, $\mathrm{SiC}$; black, diamond) grains are observed, and their relative densities $D_{\mathrm{r}}$ are also shown on the right side of the photograph. In Process (I), a high $D_{\mathrm{r}}(93.3 \%)$ is achieved in diamond $/ \mathrm{SiC}=65 / 35 \mathrm{vol} \%$, and in Process (II) a high $D_{\mathrm{r}}(90.7 \%)$ is achieved in diamond $/ \mathrm{SiC}$ $=50 / 50$ vol\%, as shown in Fig. 4. It is clear that a dense grain boundary consisting of fine $\mathrm{SiC}$ and small diamond grains could bring a high $D_{\mathrm{r}}$. In addition, good contact or good adhesiveness between large diamond particles and the grain boundary also significantly affects the densification. Based on these data, in the SiC-rich regions, Process (II) was expected to show higher $D_{\mathrm{r}}$ (Fig. 4). Then, the volume fractions of diamond and $\mathrm{SiC}$ of composites were estimated using an image analysis as mentioned before. Fig. 7 (a) and (b) show the representative SEM (BEI)
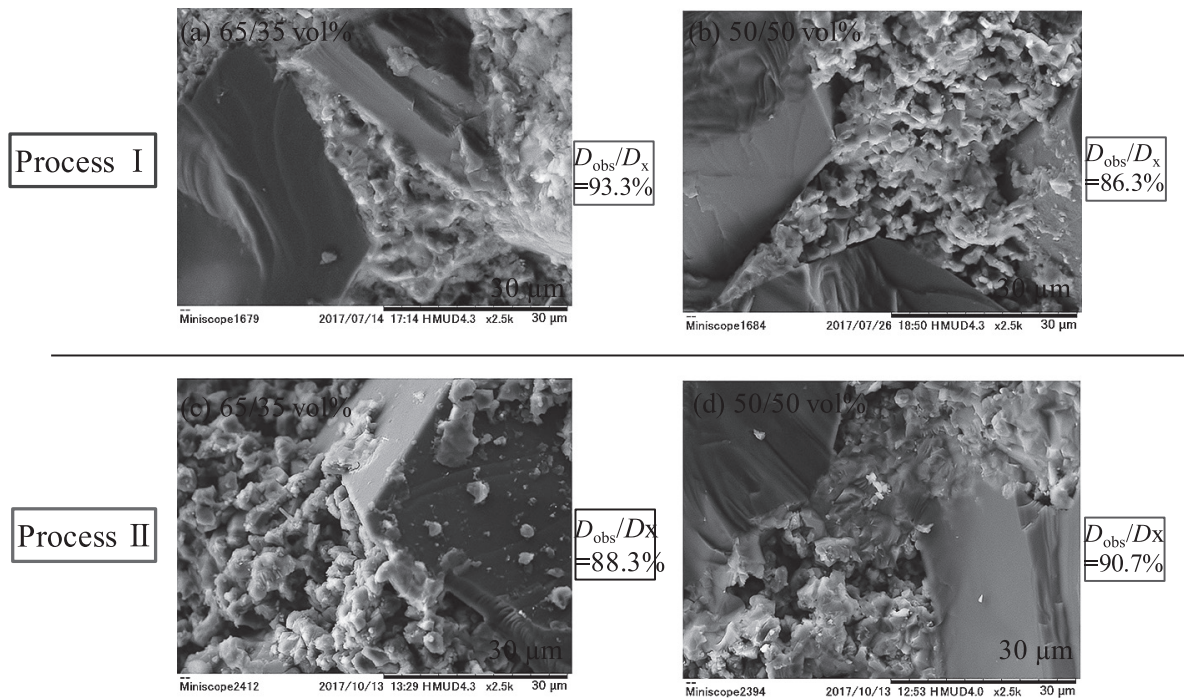

Fig. 6 SEM photographs of the fracture surfaces of diamond/SiC composites: (a) (b), calcined $\left(1223 \mathrm{~K} / 7.2 \times 10^{3} \mathrm{~s} / \mathrm{vac}\right.$.), and (c) (d) sintered by PECPS $\left(1623 \mathrm{~K} / 0.6 \times 10^{3} \mathrm{~s} / 50 \mathrm{MPa} / \mathrm{vac}\right.$.), followed by HIPing $\left(1723 \mathrm{~K} / 7.2 \times 10^{3} \mathrm{~s} / 196 \mathrm{MPa} / \mathrm{Ar}\right)$. 

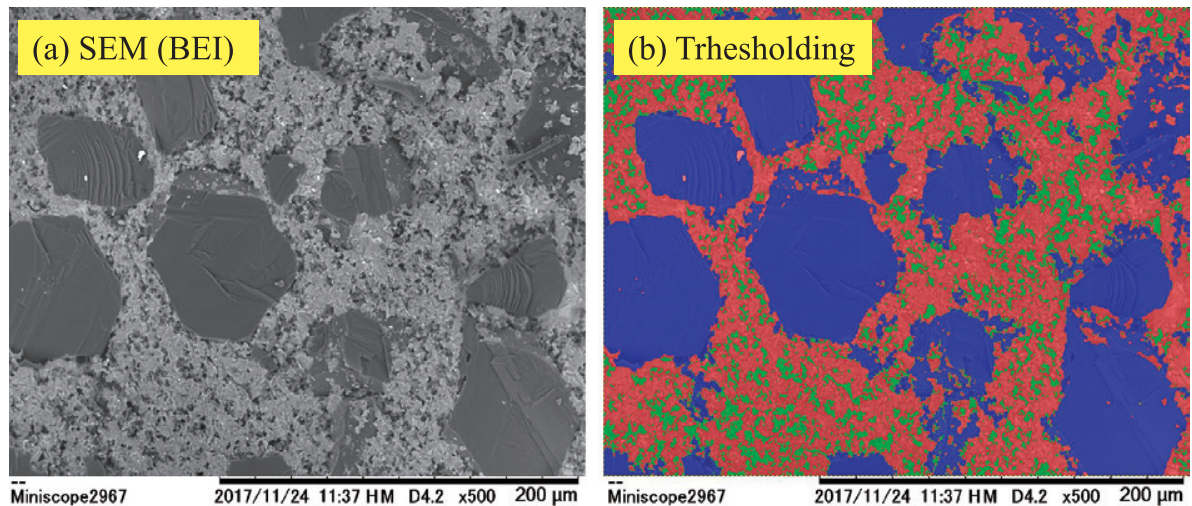

\begin{tabular}{cccccc}
\multicolumn{6}{c}{ Volume fraction calculated by trhesholding image } \\
\hline No. Area & $\begin{array}{c}\text { Total area } \\
\text { (pixcel) }\end{array}$ & $\begin{array}{c}\text { Area ratio } \\
(\%)\end{array}$ & Substance & $\begin{array}{c}\text { Area fraction } \\
(\%)\end{array}$ & $\begin{array}{c}\text { Volume fraction } \\
\text { (vol\%) }\end{array}$ \\
\hline 1 area A green & 10343 & 13.227 & diamond & 56.2 & 59.2 \\
2 area B blue & 33617 & 42.988 & & & \\
3 area C red & 34239 & 43.784 & SiC & 43.8 & 40.8 \\
\hline
\end{tabular}

Fig. 7 Representative SEM (BEI) and trhesholding (binarized) images, respectively, of diamond $/ \mathrm{SiC}=55 / 45$ vol\% composite fabricated using Process II (PECPS: $\left.1623 \mathrm{~K} / 0.6 \times 10^{3} \mathrm{~s} / 50 \mathrm{MPa} / \mathrm{vac}.\right)$, followed by $\mathrm{HIP}\left(1723 \mathrm{~K} / 7.2 \times 10^{3} \mathrm{~s} / 196 \mathrm{MPa}\right)$.

and thresholding (binarized) images, respectively, of diamond/ $\mathrm{SiC}=55 / 45 \mathrm{vol} \%$ composite fabricated using Process II (PECPS: $1623 \mathrm{~K} / 0.6 \times 10^{3} \mathrm{~s} / 50 \mathrm{MPa} / \mathrm{vac}$.), followed by HIP $(1723 \mathrm{~K} / 7.2$ $\times 10^{3} \mathrm{~s} / 196 \mathrm{MPa}$ ). In Fig. 7 (a), black fine particles in the matrix, gray large and small particles, and the fine matrix were classified into three categories, area $\mathrm{A}$ green, area $\mathrm{B}$ blue and area $\mathrm{C}$ red in Fig. 7 (b), respectively. As both area A and B are corresponding to diamond, and area $\mathrm{C}$ to $\mathrm{SiC}$, diamond and $\mathrm{SiC}$ occupy $56.2 \%$ and $43.8 \%$ area fractions, respectively as shown in Table below Fig. 7 (a) and (b). If we presume that law of similarity between twodimension of area and three-dimension of volume, i.e., $1: \mathrm{x}^{2}$ for 2 dimension shape, then similarity rate in a 3 dimension is $1: x^{3}$. For example, two circles with the radius ratio of $1: x$, then their areas are $1: x^{2}$, furthermore, the volume ratio of spheres with the same radius ratio are $1: \mathrm{x}^{3}$. When this law of similarity can be applied to this image analysis, the volume fraction of diamond to $\mathrm{SiC}$ is $59.2 / 40.8$ vol\%; these values are not so bad in light of a small amount of Si and graphite particles detected in the composites by XRD. Afterward, the calculation of theoretical density of composites has been performed under the presumption that composites consisted of basically diamond and $\mathrm{SiC}$, or in the case of $\mathrm{B}_{4} \mathrm{C}$ added composite, including the $\mathrm{B}_{4} \mathrm{C}$, small amounts of other chemical compounds have been ignored.

The dependence on diamond powder size was investigated next. Fig. 8 displays the $D_{\mathrm{r}}$ of diamond $/ \mathrm{SiC}=55 / 45 \mathrm{vol} \%$ composites, as shown by the lower white circles and squares just after PECPS $\left(1623 \mathrm{~K} / 0.6 \times 10^{3} \mathrm{~s} / 50 \mathrm{MPa} / \mathrm{vac}\right.$.), and by the upper black circles, triangles, and squares followed by HIP $\left(1723 \mathrm{~K} / 7.2 \times 10^{3} \mathrm{~s} / 196 \mathrm{MPa}\right)$. They were fabricated using pulverized $\mathrm{Si}$ and diamond powders of

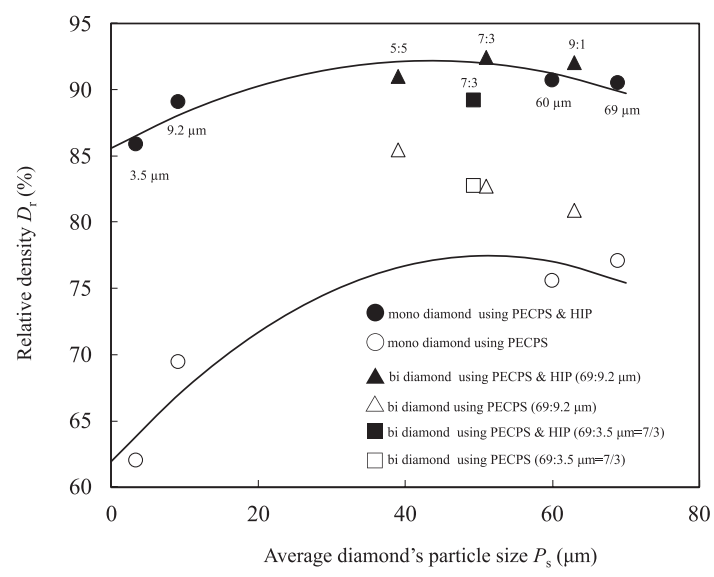

Fig. 8 Relative density of diamond $/ \mathrm{SiC}=55 / 45$ vol $\%$ composites fabricated from diamond powders of various particle sizes by PECPS $\left(1623 \mathrm{~K} / 50 \mathrm{MPa} / 0.6 \times 10^{3} \mathrm{~s} / \mathrm{vac}\right.$.), followed by HIP $\left(1723 \mathrm{~K} / 7.2 \times 10^{3} \mathrm{~s} / 196 \mathrm{MPa}\right)$.

various particle sizes. In Fig. 8, both the left and right sides, i.e., the smaller and larger powders, consisted of diamonds with monomodal particles. On the other hand, a few squares and triangles represent a bi-modal $P_{\mathrm{s}}$ distribution, and numerical numbers above the marks indicate the diamond content ratio of large vs. small powders. It is clear that the composites obtained from the smaller diamonds gave lower $D_{\mathrm{r}}$, and that the larger diamond resulted in higher $D_{\mathrm{r}}$ of up to $90 \%$ after HIP. On the other hand, the bi-modal distribution with an average $P_{\mathrm{s}}$ of around $51 \mu \mathrm{m}(69: 9.2 \mu \mathrm{m} \phi=7: 3$ ratio) brought a high $D_{\mathrm{r}}$ value of around $93 \%$, although the $D_{\mathrm{r}}$ value just after PECPS (83\%) is lower than that $(85 \%)$ of other average $P_{\mathrm{s}}(40 \mu \mathrm{m})$. 
This could be explained in terms of the re-arrangement of diamond particles in liquid Si during isostatic higher pressure (196 MPa) of HIP at $1723 \mathrm{~K}$ compared to the lower pressure (50 MPa) of uniaxial pressing of PECPS at $1623 \mathrm{~K}$. It looks strange that even though the average $P_{\mathrm{s}}$ is nearly the same as $50 \mu \mathrm{m}$, the $D_{\mathrm{r}}$ values after HIP differ between the composite from bi-modal diamond $(69: 3.5 \mu \mathrm{m} \phi=7: 3$ ratio), black square, around $88 \%$; and the composite from $(69: 9.2 \mu \mathrm{m} \phi=7: 3$ ratio), black triangle, around $93 \%$ from the theoretical expectation. The highest $D_{\mathrm{r}}$ of composites made from large and small sphere particles, i.e., with bi-modal particle size distribution, can be given at a large:small sphere volume ratio of around 7:3. Also, a higher $D_{\mathrm{r}}$ value can be achieved at a higher ratio of $P_{1}: P_{\mathrm{s}}$.

In order to improve the hardness of composites, we had already considered adding third component particles to the matrix. The criteria for such particles were i) they must be harder than $\mathrm{SiC}\left(H_{\mathrm{v}}\right.$ : $28 \mathrm{GPa}$ in Table 1), and they must offer high chemical stability both ii) at a high temperature of $1723 \mathrm{~K}$ and iii) in the diamond/ $\mathrm{SiC}$ matrix. One of the main reasons we selected $\mathrm{B}_{4} \mathrm{C}$ was that it is carbide, the same as diamond and $\mathrm{SiC}$. As shown in Table 1, $H_{v}$ of $\mathrm{B}_{4} \mathrm{C}$ is $33.5 \mathrm{GPa}^{12,13)}$ and its melting temperature is $2723 \mathrm{~K}$. The other physical properties, such as Young's modulus $E$ and thermal expansion coefficient $\alpha$, are $385 \mathrm{GPa}$ and $2.3 \times 10^{-6} \mathrm{~K}^{-1}$, respectively ${ }^{19)}$.

In the case of the addition of $\mathrm{B}_{4} \mathrm{C}(0.5 \mu \mathrm{m} \phi)$, a preliminary experiment was previously performed. Fig. 9 represents XRD patterns of the composites with diamond $/ \mathrm{SiC}=55 / 45 \mathrm{vol} \%$ with $7.0 \mathrm{vol} \% \mathrm{~B}_{4} \mathrm{C}$ as an inner proportion, using the bi-modal diamonds a) $(69: 3.5 \mu \mathrm{m} \phi=7: 3)$ and b) $(69: 9.2 \mu \mathrm{m} \phi=7: 3)$; they were fabricated by PECPS $\left(1623 \mathrm{~K} / 0.6 \times 10^{3} \mathrm{~s} / 50 \mathrm{MPa} / \mathrm{vac}\right.$. $)$ and HIP $\left(1723 \mathrm{~K} / 7.2 \times 10^{3} \mathrm{~s} / 196 \mathrm{MPa} / \mathrm{Ar}\right)$. From these data, it is easily

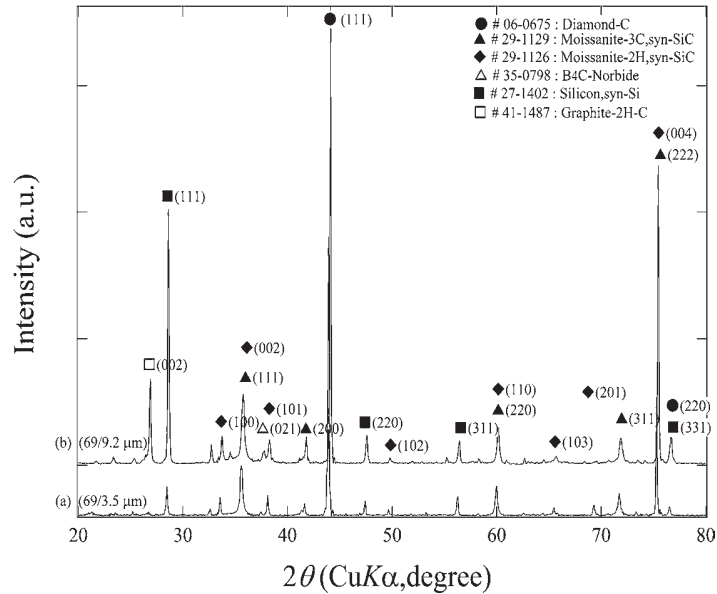

Fig. 9 XRD patterns of diamond $/ \mathrm{SiC}=55 / 45$ vol $\%$ composites added with $\mathrm{B}_{4} \mathrm{C}$ : (a) (f) sintered by PECPS $\left(1623 \mathrm{~K} / 50 \mathrm{MPa} / 0.6 \times 10^{3} \mathrm{~s} /\right.$ vac.) and sintered by HIP $\left(1723 \mathrm{~K} / 7.2 \times 10^{3} \mathrm{~s} / 196 \mathrm{MPa} / \mathrm{Ar}\right)$.

recognized that the former shows i) much smaller diffraction intensities of $\mathrm{Si}$ and carbon and ii) a much higher $\mathrm{SiC}$ phase. These results suggested that when we add a small amount of $\mathrm{B}_{4} \mathrm{C}$ to the composite as the starting material of diamond, the mixed powders of $(69: 3.5 \mu \mathrm{m} \phi=7: 3)$ would be better than those of $(69: 9.2 \mu \mathrm{m} \phi$ $=7: 3$ ). This was proved by microstructural observation. Fig. 10 shows SEM (back-scattered electron image: BEI) photographs of the polished surfaces of [diamond $/ \mathrm{SiC}=55 / 45 \mathrm{vol} \%$ ] $+7 \mathrm{vol} \%$ $\mathrm{B}_{4} \mathrm{C}$ composites made from the diamond mixtures of $(69: 3.5 \mu \mathrm{m} \phi$ $=7: 3)(\mathrm{a}) \sim(\mathrm{c})$ and $(69: 9.2 \mu \mathrm{m} \phi=7: 3)(\mathrm{d}) \sim(\mathrm{f})$ taken under low $(0.5$ $\left.\times 10^{3}=0.5 \mathrm{k}\right)$, middle $(1.0 \mathrm{k})$, and high $(2.5 \mathrm{k})$ magnifications By comparing (a) and (d), small black particles (diamonds) are scarcely present in the former, suggesting that small diamonds changed into $\mathrm{SiC}$; (b) and (e), a larger number of small white particles $(\mathrm{Si})$ are observed in the latter than in the former; (c)
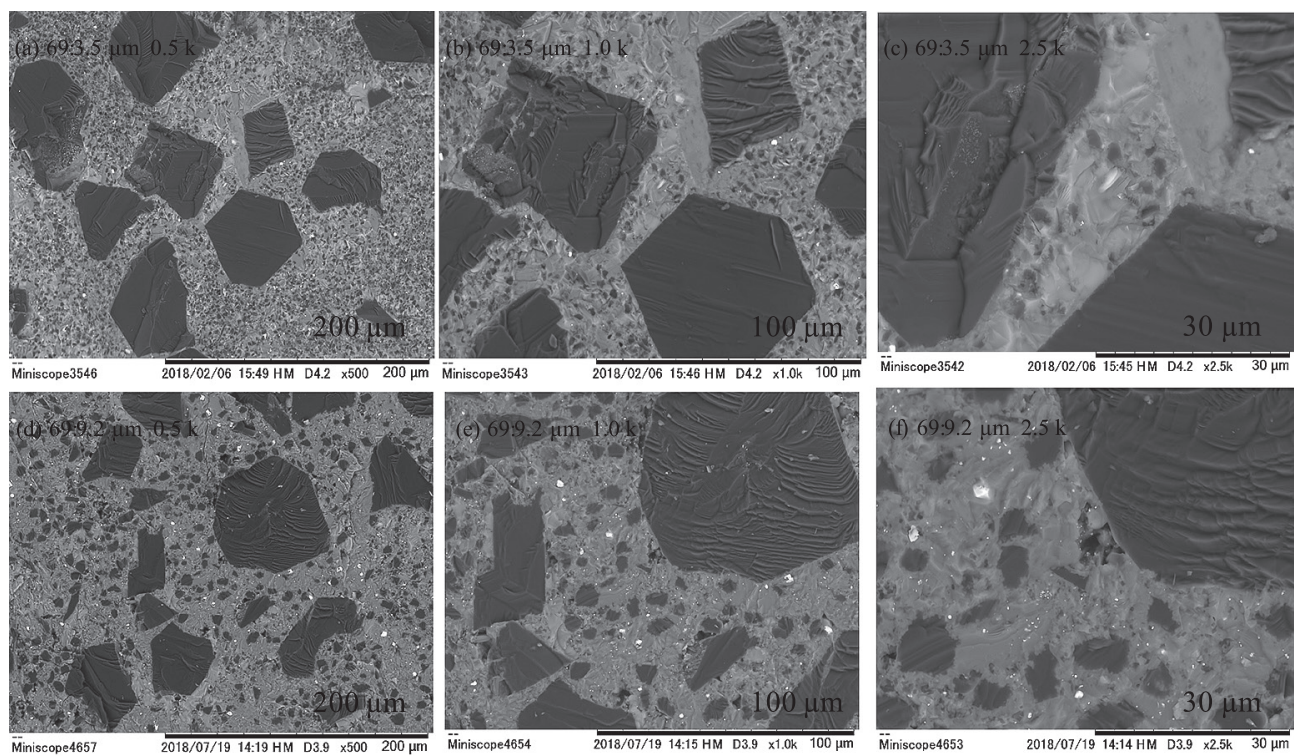

Fig. 10 SEM (BEI) photographs of $\left[(\right.$ diamond $\left./ \mathrm{SiC}=55 / 45 \mathrm{vol} \%) / \mathrm{B}_{4} \mathrm{C}\right]=93 / 7 \mathrm{vol} \%$ composites fabricated by PECPS $\left(1623 \mathrm{~K} / 50 \mathrm{MPa} / 0.6 \times 10^{3} \mathrm{~s} / \mathrm{vac}\right.$. $)$ and sintered by HIP $\left(1723 \mathrm{~K} / 7.2 \times 10^{3} \mathrm{~s} / 196 \mathrm{MPa} / \mathrm{Ar}\right)$. 
and (f), a dense grain boundary layer is seen in the former. These photographs also support the XRD results shown in Fig. 9.

Then $\mathrm{B}_{4} \mathrm{C}$-added diamond (69:3.5 $\left.\mu \mathrm{m} \phi=7: 3\right) / \mathrm{SiC}=55 / 45 \mathrm{vol} \%$ composites were fabricated in the same manner as described above. The $\mathrm{B}_{4} \mathrm{C}$ contents were increased by $10 \mathrm{vol} \%$ with an inner proportion. Fig. 11 shows the XRD patterns of these $\mathrm{B}_{4} \mathrm{C}$-added composites sintered by PECPS $\left(1623 \mathrm{~K} / 0.6 \times 10^{3} \mathrm{~s} / 50 \mathrm{MPa} / \mathrm{vac}\right.$. and HIP $\left(1723 \mathrm{~K} / 7.2 \times 10^{3} \mathrm{~s} / 196 \mathrm{MPa} / \mathrm{Ar}\right)$. As the amount of $\mathrm{B}_{4} \mathrm{C}$ increased, both Si (PDF: \#27-1402) and $\mathrm{B}_{4} \mathrm{C}$ (PDF: \#35-0798) diffraction peaks occurred around $2 \theta=28.4^{\circ}$ and $2 \theta=37.4^{\circ}$, respectively, although without $\mathrm{B}_{4} \mathrm{C}$ addition a small diffraction peak of $\mathrm{Si}$ at $28.4^{\circ}$ is recoginized. Furthermore, it should be noted that the $\mathrm{B}_{4} \mathrm{C}$ addition enhanced the formation of both cubic (PDF: \#29-1129) and hexagonal (PDF: \#29-1126) SiC. After HIPing at $1723 \mathrm{~K}, \mathrm{~B}_{4} \mathrm{C}, \mathrm{SiC}$, and graphite were recognized in the composites up to 5 vol\% addition. Then, the values of $D_{\text {obs }}$ and $D_{\mathrm{x}}$ of the composites were measured and calculated. In the calculation of $D_{\mathrm{x}}$, a small amount of graphite was ignored and $D_{\mathrm{x}}$ of cubic $\alpha$-SiC was assumed to be the same as that of hexagonal $\beta-\mathrm{SiC}$.

Fig. 12 represents the $D_{\mathrm{r}}$ values of the composites before and after HIP, shown as round white and black circles, respectively, as a function of $\mathrm{B}_{4} \mathrm{C}$ content. The $D_{\mathrm{r}}$ value decreased once at 1.0 vol $\% \mathrm{~B}_{4} \mathrm{C}$ and then gradually increased up to about $95.0 \%$ with $10.0 \mathrm{vol} \%$ addition. In this figure, the $D_{\mathrm{r}}$ values of composites made from the mixure of $(69: 9.2 \mu \mathrm{m} \phi=7: 3)$ diamonds are also plotted as black triangles, with 0 and $7 \mathrm{vol} \% \mathrm{~B}_{4} \mathrm{C}$ addition as a reference. Though there is little difference in $D_{\mathrm{r}}$ values between $(69: 3.5 \mu \mathrm{m} \phi=7: 3)$ and $(69: 9.2 \mu \mathrm{m} \phi=7: 3)$ diamonds derived composites at $0 \mathrm{vol} \%$, at $7 \mathrm{vol} \% \mathrm{~B}_{4} \mathrm{C}$ addition, nearly the same values are observed in the HIP-sintered samples, as expected. This $D_{\mathrm{r}}$ increase by $\mathrm{B}_{4} \mathrm{C}$ addition can be explained partially as follows. $\mathrm{B}_{4} \mathrm{C}$ particles acted as sintering aids in the same manner as a small amount of the combined addition of $\mathrm{Al}_{4} \mathrm{C}_{3}-\mathrm{B}_{4} \mathrm{C}-\mathrm{C}$ for $\mathrm{SiC}^{20)}$ and suppressed the reduction in volume change $\Delta V / V_{0}=-19.5 \%$, followed by the formation of $\beta$-SiC from the mixture of diamond and $\mathrm{Si}$, i.e., $\mathrm{C}$ (diamond) $+\mathrm{Si} \rightarrow \beta-\mathrm{SiC}$. Here in this calculation the values of (diamond C: atomic weight a.t.: 12.01, theoretical density $D_{\mathrm{x}}: 3.515 \mathrm{Mg} \cdot \mathrm{m}^{-3}$, PDF: \#06-0675), (Si: a.t.: 28.09, $D_{\mathrm{x}}$ : 2.329, PDF: \#27-1402), (SiC: a.t.: 40.1, $D_{\mathrm{x}}: 3.211$, PDF: \#29-1129) were used. For example, when $1,3,5,7$, and 10 vol $\% \mathrm{~B}_{4} \mathrm{C}$ are added to the diamond $/ \mathrm{SiC}=55 / 45$ vol $\%$ composite, $\Delta V / V_{0}$ values decrease gradually with increasing $\mathrm{B}_{4} \mathrm{C}$ addition; $-9.70 \%$ ( 0 vol\%), $-9.61 \%$ ( 1 vol $\%$ ), $-9.43 \%$ (3 vol $\%$ ), $-9.26 \%$ ( 5 vol $\%$ ), $-9.08 \%$ $(7 \mathrm{vol} \%)$, and $-8.81 \%\left(10 \mathrm{vol} \% \mathrm{~B}_{4} \mathrm{C}\right)$. Thus, it is clear that even a $10 \mathrm{vol} \% \mathrm{~B}_{4} \mathrm{C}$ addition brings about the suppression of the reduction in volume change to around $0.89 \%$. Therefore, $\mathrm{B}_{4} \mathrm{C}$ might act as a sintering aid for $\mathrm{SiC}$.

The composites' microstructures were then observed. Fig. 13 shows SEM photographs of the composites with the compositions of [diamond $(69: 3.5 \mu \mathrm{m} \phi=7: 3) / \mathrm{SiC}=55 / 45 \mathrm{vol} \%] / \mathrm{B}_{4} \mathrm{C}=$

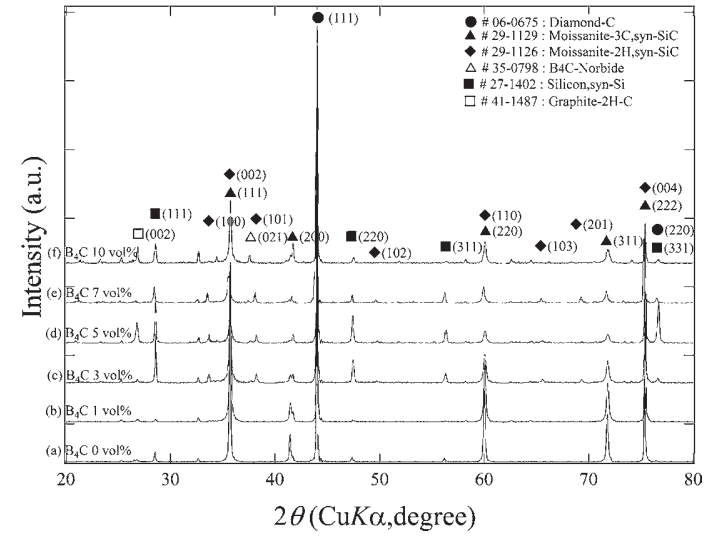

Fig. 11 XRD patterns of diamond $/ \mathrm{SiC}=55 / 45$ vol $\%$ composites with $\mathrm{B}_{4} \mathrm{C}$ added: (a) (f) sintered by PECPS $\left(1623 \mathrm{~K} / 0.6 \times 10^{3} \mathrm{~s} / 50 \mathrm{MPa} /\right.$ vac.) and sintered by HIP $\left(1723 \mathrm{~K} / 7.2 \times 10^{3} \mathrm{~s} / 196 \mathrm{MPa} / \mathrm{Ar}\right)$

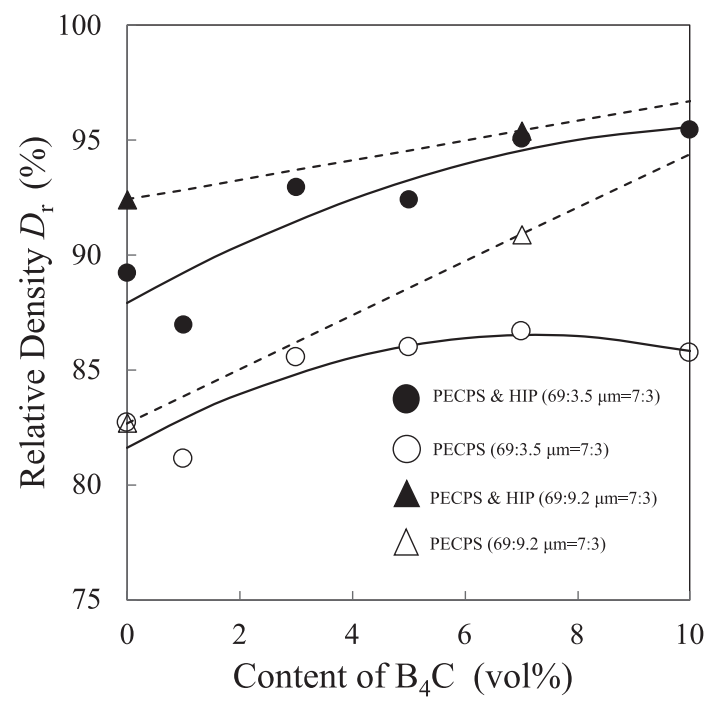

Fig. 12 Relative densities of [diamond $(69: 3.5 \mu \mathrm{m} \phi=7: 3) / \mathrm{SiC}=$ $55 / 45 \mathrm{vol} \%] / \mathrm{B}_{4} \mathrm{C}$ composites as a function of $\mathrm{B}_{4} \mathrm{C}$ content.

100/0 90/10 vol\%, fabricated by PECPS and HIP; (a) 0, (b) 1.0, (c) 3.0 , (d) 5.0 , (d) 7.0, and (e) $10 \mathrm{vol} \% \mathrm{~B}_{4} \mathrm{C}$. At first it is clear that dense microstructures are recognized as compared with those without $\mathrm{B}_{4} \mathrm{C}$ addition in Fig. 6. As described before, a backscattered electron image (BEI) proves that the heavier elements give brighter images than the lighter elements. Therefore, both the large dark gray blocks and the small particles in the grain boundaries are large and small diamonds, respectively, and the bright grain-boundary matrix might be SiC. However, in these photographs $\mathrm{B}_{4} \mathrm{C}$ particles could not be recognized or distinguished from small diamonds among the grain boundaries because both particles are fine and have nearly the same light elements as diamond.

Then a mechanical property, the hardness of the composites with the [diamond $(69: 3.5 \mu \mathrm{m} \phi=7: 3) / \mathrm{SiC}=55 / 45 \mathrm{vol} \%] / \mathrm{B}_{4} \mathrm{C}=$ 100/0 90/10 vol\%, was evaluated. Vickers hardness $H_{\mathrm{v}}$ is shown in Fig. 14 (a). Though some scattering in $H_{\mathrm{v}}$ values at 1, 5, and 10 vol\% is observed, with increasing $\mathrm{B}_{4} \mathrm{C}$ content their average 

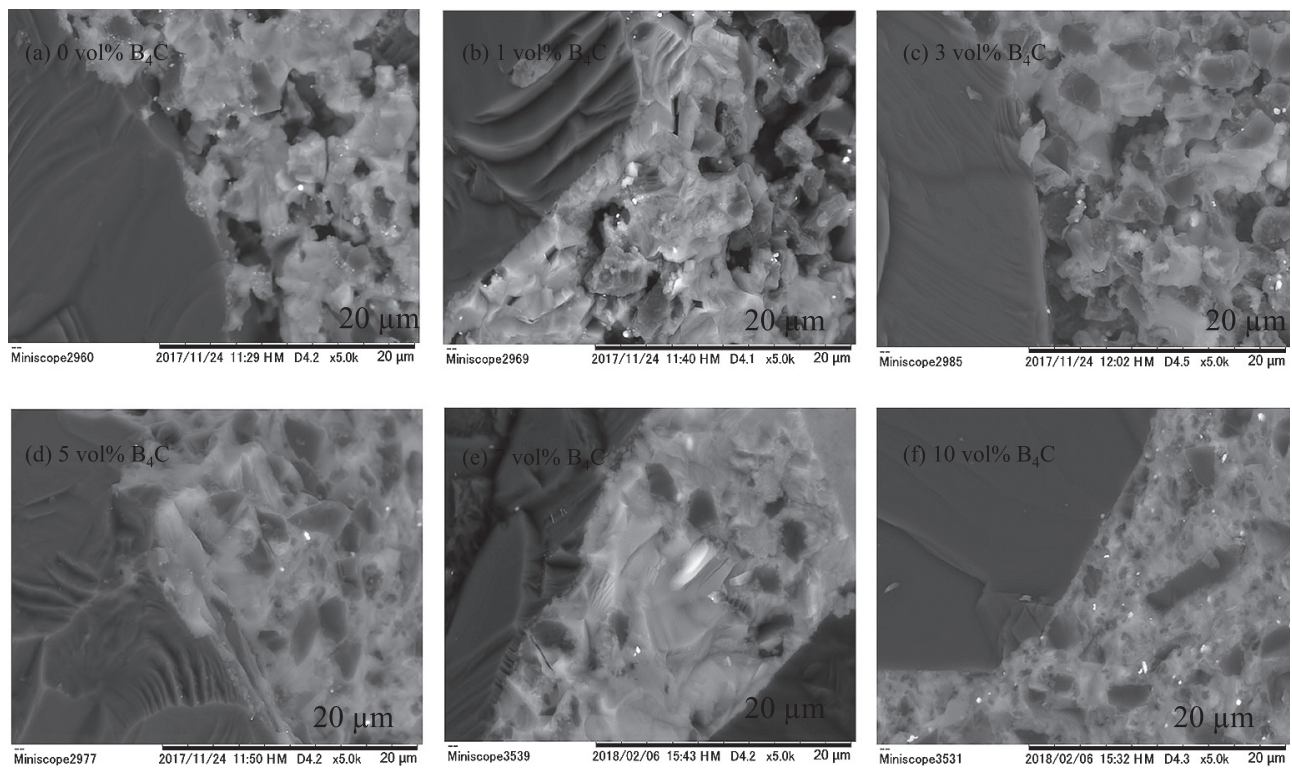

Fig. 13 SEM (BEI) photographs of $\left[(\right.$ diamond $\left./ \mathrm{SiC}=55 / 45 \mathrm{vol} \%) / \mathrm{B}_{4} \mathrm{C}\right]$ composites fabricated by PECPS $\left(1623 \mathrm{~K} / 0.6 \times 10^{3} \mathrm{~s} / 50 \mathrm{MPa} / \mathrm{vac}\right.$. $)$ and sintered by $\operatorname{HIP}\left(1723 \mathrm{~K} / 7.2 \times 10^{3} \mathrm{~s} / 196 \mathrm{MPa} / \mathrm{Ar}\right)$.

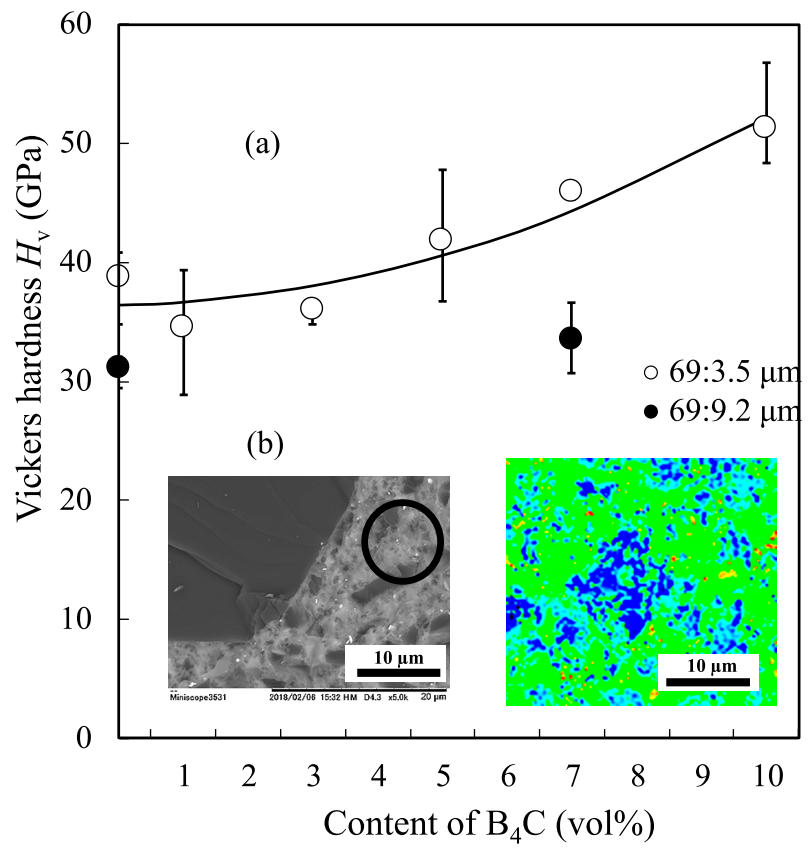

Fig. 14 (a) Vickers hardness $H_{\mathrm{v}}$ of [diamond (69:3.5 $\left.\mu \mathrm{m} \phi=7: 3\right) / \mathrm{SiC}$ $=55 / 45 \mathrm{vol} \%] / \mathrm{B}_{4} \mathrm{C}$ and [diamond $(69: 9.2 \mu \mathrm{m} \phi=7: 3) / \mathrm{SiC}=$ $55 / 45 \mathrm{vol} \%] / \mathrm{B}_{4} \mathrm{C}$ composites as shown by white and black circles, respectively. (b) SEM photos of Vickers indent under low (left) and high (right) magnifications, respectively.

$H_{\mathrm{v}}$ values increased gradually from around 38.7 to $51.3 \mathrm{GPa}$ at $10 \mathrm{vol} \% \mathrm{~B}_{4} \mathrm{C}$ addition. It should be noted that the highest $H_{\mathrm{v}}$ value was $51.3 \mathrm{GPa}$. As a reference, $H_{\mathrm{v}}$ values of composites with the [diamond $(69: 9.2 \mu \mathrm{m} \phi=7: 3) / \mathrm{SiC}=55 / 45 \mathrm{vol} \%] / \mathrm{B}_{4} \mathrm{C}=100 / 0$ and 93/7 vol\%, 31.1 and 33.4, are also displayed in Fig. 14 (a); both values are much lower than those of the former. A comparison of these values of the two groups indicates that this $H_{\mathrm{v}}$ increment might originate from not only the harder $\mathrm{B}_{4} \mathrm{C}$ addition compared to that of $\mathrm{SiC}$, i.e., a $3.3 \mathrm{GPa}$ increase from 31.1 to $33.4 \mathrm{GPa}$, but also from the effect of the $\mathrm{SiC}$ matrix microstructural evolution originating from the difference in starting diamond powder mixtures between $(69: 3.5 \mu \mathrm{m} \phi=7: 3)$ and $(69: 9.2 \mu \mathrm{m} \phi=7: 3)$; fine diamonds in the former are much more active during the liquidphase reaction sintering of $\mathrm{Si}$ with diamond than fine diamonds in the latter. Fig. 14 (b) shows laser microscopic images of "Vickers indent $\left(H_{\mathrm{v}}: 51.3 \mathrm{GPa}\right)$ " on the polished surface through low (left) and high (right) magnifications. From the left image, it is clear that the $H_{\mathrm{v}}$ indent in the black circle had been formed in the $\mathrm{SiC}$ matrix. The indent size in the right image is very small, proving high hardness. These photographs also indicate that small diamond, $\mathrm{B}_{4} \mathrm{C}$, and $\mathrm{SiC}$ are homogeneously dispersed. This homogeneous dispersion, the thermal expansion coefficient $\alpha$ difference between $\operatorname{SiC}\left(\alpha=4.5 \times 10^{-6} \mathrm{~K}^{-1}\right)^{19)}$ and $\mathrm{B}_{4} \mathrm{C}\left(\alpha=2.3 \times 10^{-6} \mathrm{~K}^{-1}\right)^{17)}$, and the high Young's modulus $\left(E_{(\mathrm{B} 4 \mathrm{C})} 385 \sim E_{(\mathrm{SiC})} 430 \mathrm{GPa}^{19,21)}\right.$, Table 1) might induce high compression stress into the $\mathrm{SiC} / \mathrm{B}_{4} \mathrm{C}$ grain boundary, which might bring about a higher $H_{\mathrm{v}}$ value than those (about $37 \mathrm{GPa}$ ) reported previously ${ }^{5}$.

\section{Conclusions}

Dense diamond $/ \mathrm{SiC}=55 / 45 \mathrm{vol} \%$ composites were fabricated from mixtures of various kinds of diamond powders, such as monomodal, 3.5 69 $\mu \mathrm{m}$ and bi-modal (69:3.5 $\mu \mathrm{m} \phi=7: 3),(69: 9.2 \mu \mathrm{m} \phi$ $=7: 3)$, and $\mathrm{Si}(0.6 \mu \mathrm{m} \phi)$ powders using pulsed electric-current pressure sintering (PECPS) at $1623 \mathrm{~K}$ for $0.6 \times 10^{3} \mathrm{~s}$ under $50 \mathrm{MPa}$ in a vacuum, followed by HIP at $1723 \mathrm{~K}$ for $7.2 \times 10^{3} \mathrm{~s}$ under $196 \mathrm{MPa}$ in Ar with liquid-phase sintering. This composite had a high Vickers hardness $H_{\mathrm{v}}$ of $38.7 \mathrm{GPa}$. Furthermore, a small addition of $\mathrm{B}_{4} \mathrm{C}$ enhanced the $H_{\mathrm{v}}$ up to about $51.3 \mathrm{GPa}$ due to high compression stress induced into the $\mathrm{SiC} / \mathrm{B}_{4} \mathrm{C}$ boundary matrix. 
Furthermore, if a relative density of more than $99.5 \%$ can be achieved in these composites, $H_{\mathrm{v}}$ values higher than $60 \mathrm{GPa}$ may be a dream come true.

\section{Acknowledgment}

This work was financially supported by the Program for the Strategic Research Foundation at Private Universities, 20132017, from the Ministry of Education, Culture, Sports, Science, and Technology, Japan (MEXT). The authors thank Ms. M. Toda and Ms. J. Morita of the Doshisha University Research Centre for Interfacial Phenomena for FE-SEM and laser microscope observations of the samples.

\section{References}

1) F. P. Bundy, H. T. Hall, H. M. Strong, R. H. Wentorf Jr.: Nature, 176 (1955) 51-55.

2) H. Sumiya, N. Toda, S. Satoh: J. Crystal Growth, 237-239 (2002) 1281-1285.

3) R. Berman, F. Simon: Zeit. Electrochem., 59 (1950) 333-38.

4) S. Kume, K. Suzuki, H. Yoshida: pp. 53-55 in Physical Properties of Composites, Proceedings of the $125^{\text {th }}$ TMS Annual Meetings Symposium, The Minerals, Metals and Materials Society, Warrendale, PA, 1996.

5) M. Shimono, S. Kume: J. Am. Ceram. Soc., 87 (2004) $752-$ 755 .

6) M. Tokita: J. Soc. Powder Tech. Jpn., 30 (1993) 790-804.

7) K. Hirota, K. Shibaya, M. Kato, H. Taguchi: Processing and Properties of Advanced Ceramics and Composites VI, The American Ceramic Society's Ceramic Transactions, 249 (2013)3-13.
8) Y. Zhou, K. Hirao, M. Toriyama, H. Tanaka: J. Am. Ceram. Soc., 83 (2000) 654-656.

9) K. Hirota, Y. Takaura, M. Kato, Y. Miyamoto: J Mater Sci, 42 (2007) 4792-4800.

10) K. Hirota, H. Hara, M. Kato: Materials Science and Engineering, A 458 (2007) 216-225.

11) K. Hirota, T. Shibata, M. Kato, T. Nishimura: Materials Science and Technology (MS\&T) (2007) 309-320.

12) K. Hirota, Y. Nakayama, S. Nakane, M. Kato, T. Nishimura: Int. J. Appl. Ceram. Technol., 6 (2009) 607-616.

13) K. Hirota, M. Shima, X. Chen, N. Goto, M. Kato, T. Nishimura: Mater. Sci. Eng. A, 628 (2015) 41-49.

14) K. Hirota, M. Obata, M. Kato, H. Taguchi: Int. J. Appl. Technol. Online, 6 DEC (2011) 1-13.

15) R. Ohshima, H. Yamanaka, S. Hosomi: J. Soc. Mat. Sci., Japan, 49 (2000) 602-605.

16) V. Novikov: Naukova Dumka (1987) 147.

17) S. Yerazunis, J. W. Bartlett, A. H. Nissan: Nature, 195 (1962) 33-35.

18) J. E. Marion, C. H. Hsueh, A. G. Evans: J. Am. Ceram. Soc., 70 (1987) 708-713.

19) J. F. Shackelford, W. Alexander: CRC Materials Science and Engineering Handbook 3rd ed., Table 116. Thermal expansion of ceramics, CRC Press, Boca Raton, Florida 3343, 2001, p. 449

20) Y. Zhou, H. Tanaka, S. Otani, Y. Bando: J. Am. Ceram. Soc., 82 (1999) 1959-1964.

21) J. F. Shackelford, W. Alexander: CRC Materials Science and Engineering Handbook 3rd ed., Table 116. Thermal expansion of ceramics, CRC Press, Boca Raton, Florida 3343, 2001, p. 449. 